2013-05

\title{
Domestic source of phosphorus to sewage treatment works
}

\author{
Comber, Sean
}

http://hdl.handle.net/10026.1/3792

10.1080/09593330.2012.747003

Environmental Technology

Informa UK Limited

All content in PEARL is protected by copyright law. Author manuscripts are made available in accordance with publisher policies. Please cite only the published version using the details provided on the item record or document. In the absence of an open licence (e.g. Creative Commons), permissions for further reuse of content should be sought from the publisher or author. 
This article was downloaded by: [Univ of Plymouth]

On: 07 January 2013, At: 23:48

Publisher: Taylor \& Francis

Informa Ltd Registered in England and Wales Registered Number: 1072954 Registered office: Mortimer House, 37-41 Mortimer Street, London W1T 3J H, UK

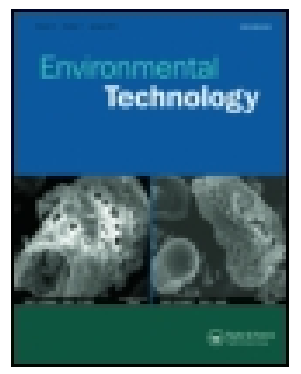

\title{
Environmental Technology
}

Publication details, including instructions for authors and subscription information:

http:// www.tandfonline.com/loi/tent20

\section{Domestic Source of Phosphorus to Sewage Treatment Works}

\author{
Dr Sean Comber ${ }^{a}$, Mr Michael Gardner ${ }^{b}$, Mrs Karyn Georges ${ }^{c}, \operatorname{Dr}^{\text {David Blackwood }}{ }^{c} \&$ Dr \\ Daniel Gilmour ${ }^{c}$ \\ ${ }^{a}$ Atkins Limited, Chilbrook Oasis Business Park, Oxford, OX29 4AH \\ ${ }^{b}$ Atkins Limited, The Hub, 500 Park Avenue, Aztec West, Bristol, BS32 4RZ, UK \\ ${ }^{\mathrm{C}}$ Urban Water Technology Centre, University of Abertay Dundee, Level 5 Kydd Building, Bell \\ Street, Dundee, DD1 1HG \\ Accepted author version posted online: 14 Nov 2012.
}

To cite this article: Dr Sean Comber, Mr Michael Gardner, Mrs Karyn Georges, Dr David Blackwood \& Dr Daniel Gilmour (2012): Domestic Source of Phosphorus to Sewage Treatment Works, Environmental Technology, DOI: 10.1080/ 09593330.2012.747003

To link to this article: http:// dx.doi. org/ 10.1080/09593330.2012.747003

Disclaimer: This is a version of an unedited manuscript that has been accepted for publication. As a service to authors and researchers we are providing this version of the accepted manuscript (AM). Copyediting, typesetting, and review of the resulting proof will be undertaken on this manuscript before final publication of the Version of Record (VoR). During production and pre-press, errors may be discovered which could affect the content, and all legal disclaimers that apply to the journal relate to this version also.

\section{PLEASE SCROLL DOWN FOR ARTICLE}

Full terms and conditions of use: http://www.tandfonline.com/page/terms-and-conditions

This article may be used for research, teaching, and private study purposes. Any substantial or systematic reproduction, redistribution, reselling, loan, sub-licensing, systematic supply, or distribution in any form to anyone is expressly forbidden.

The publisher does not give any warranty express or implied or make any representation that the contents will be complete or accurate or up to date. The accuracy of any instructions, formulae, and drug doses should be independently verified with primary sources. The publisher shall not be liable for any loss, actions, claims, proceedings, demand, or costs or damages whatsoever or howsoever caused arising directly or indirectly in connection with or arising out of the use of this material. 
Domestic Source of Phosphorus to Sewage Treatment Works

Dr Sean Comber ${ }^{1}$, Mr Michael Gardner², Mrs Karyn Georges², Dr David Blackwood ${ }^{3}$, Dr Daniel 5 Gilmour $^{3}$

${ }^{1}$ Corresponding author: Atkins Limited, Chilbrook Oasis Business Park, Oxford, OX29 4AH. New address below.

$9 \quad{ }^{2}$ Atkins Limited, The Hub, 500 Park Avenue, Aztec West, Bristol, BS32 4RZ,

10 UK

$11{ }^{3}$ Urban Water Technology Centre, University of Abertay Dundee, Level 5 Kydd Building, Bell Street, 12 Dundee, DD1 1HG

Present address: B525 Portland Square, Plymouth University, Drake Circus, Plymouth, PL4 8AA, UK. Tel: +44(0)1752585974, Fax: +44(0)1752584710.

Key words: Phosphorus, source, apportionment, domestic, sewage, loads

\section{Abstract}

Phosphorus is an element essential for life. Concerns regarding long term security of supply and issues related to eutrophication of surface waters once released into the aquatic environment, have led Governments considering and applying measures for reducing the use and discharge of phosphorus.

23 Examples of source control include legislation to reduce phosphorus use in domestic detergents. This research shows that other domestic sources of phosphorus also contribute significantly to the domestic load to sewer and that overall, domestic sources dominate loads to sewage treatment works. Estimates provided here show that although the natural diet contributes $40 \%$ of the domestic phosphorus load, other 
entering UK sewage treatment works each year. In the UK, food additives are estimated to contribute $29 \%$ of the domestic load, automatic dishwashing detergents contribute $9 \%$ and potentially increasing, domestic laundry $14 \%$ including contributions from phosphonates, but decreasing, phosphorus dosing to reduce lead levels in tap water $6 \%$, food waste disposed of down the drain $1 \%$ and personal care products 1\%. Although UK data is presented here, it is anticipated that similar impacts would be expected for other developed economies. Consideration of alternatives to all preventable sources of phosphorus from these sources would therefore offer potentially significant reductions in phosphorus loads to sewage treatment works and hence to the aquatic environment. Combining all source control measures and applying them to their maximum extent could potentially lead to the prevention of over 22,000 tonnes-P/year entering STW.

\section{Introduction}

Phosphorus is a naturally occurring element essential to life on earth, however, there are concerns regarding long term sustainability and reliability of supply [1]. Although essential for life, the release of excessive amounts of phosphorus into the aquatic environment via diffuse agricultural inputs or via sewage treatment works (STW) can lead to eutrophication, where by excessive growth of algae can lead to reductions in biodiversity or even death of fish populations in severe cases. The European Water Framework Directive (WFD, Directive 2000/60/EC) and other regulation such as the Urban Wastewater Treatment Directive (UWWTD, Directive 91/271/EEC) and the Habitats Directive (Directive 92/43/EEC) place pressure on dischargers to the aquatic environment to reduce inputs of phosphorus (P), amongst other substances. A 2006 report by the UK Technical Advisory Group (UKTAG), supported by river basin characterisation exercises which place water bodies into high, good, moderate, poor and bad categories, predicted that a large percentage of water bodies in England and a smaller number in Wales, Scotland and Northern Ireland are failing to achieve "good status" for phosphorus, as required under the WFD [2]. Data for 2008 available from the Environment Agency reports that 51\% of English rivers had phosphorus concentrations considered to be 'high' in other words greater than $0.1 \mathrm{mg} / \mathrm{l}$ [3]. In order to 
work towards achieving good status, varied mitigation measures will need to be identified by the Regulators (in consultation with stakeholders) to further reduce inputs of phosphorus to surface waters.

To ensure that the measures meet their objectives without incurring disproportionate costs to industry and in particular, the water industry, it is essential to derive accurate source apportionment data, so that decisions made by the regulators provide the expected environmental benefits. Measures to reduce chemical loads discharged to surface waters include (i) source control, (ii) end-of-pipe treatment at sewage treatment works and (iii) control of agricultural runoff. The most cost effective option depends on the use patterns of the chemical (whether they are used for specific purposes only or are used broadly) and how they are released into the environment (from point sources, such as STWs, or diffuse sources, e.g. agricultural run-off). For phosphorus, inputs to the environment are numerous, but, in terms of overall loads to water bodies in the UK, are dominated by point source discharges from STW and diffuse inputs from agriculture [4].

Control of industrial discharges of phosphorus to sewer is not likely to have a substantial impact because these sources are relatively minor [5]. However, benefits may be derived by applying source control measures through the reduction or removal of phosphorus-based chemicals in domestic products and wastewater. Concern regarding eutrophication of surface waters has led to a decline in usage of phosphates in laundry products (typically with zeolite-based products) culminating with the UK government deciding to limit the weight of inorganic phosphate expressed as phosphorus in domestic laundry detergents to no more that $0.4 \%$ of the weight of the detergent. Paragraph 9 of the Detergents Regulations 2010 states that it will be prohibited to place on the market a domestic laundry detergent that fails to comply with this requirement after 1 January 2015 [6]. Phosphorus, however, is still a major constituent of automatic dishwasher detergents (often present at around 30\% phosphate by weight) and is still used in the form of phosphonates (generally present as less than $5 \%$ by weight) in domestic laundry cleaning products. Phosphorus is present as a food additive in processed meats and other food products. Phosphates are also added to the water supply across most of the UK in order to ensure compliance with a 
new drinking water standard for lead of $10 \mu \mathrm{g} / \mathrm{l}$ to be introduced in December 2013 in line with World Health Organisation guidelines [7].

In order to safeguard future supplies of phosphorus as well as to make cost effective decisions regarding further reductions of phosphorus discharges to surface waters, it is first necessary accurately to quantify the most significant sources. In this study, a mass balance of phosphorus sources to STW from domestic sources is undertaken based on work sponsored by UK Water Industry Research (UKWIR) in conjunction with Scotland and Northern Ireland Forum for Environmental Research (SNIFFER) and UKTAG supported by the Environment Agency and the Scottish Environmental Protection Agency (SEPA).

\section{Methods}

To generate a mass balance for the domestic loads of phosphorus to STW a number of approaches are required utilising a broad dataset of statistics and assumptions. These are described in the following methodology section.

\section{Phosphorus in personal care products}

Phosphorus is rarely used in personal care products such as hair shampoo, conditioner, shower gel and body soap [8]. However, where added, the most common form of phosphorus found is cocamidopropyl PG-dimonium chloride phosphate [7]. Traces of this compound are also found in some hair shampoos, hand soaps, some styling gels and lotions, and hairspray. Traces of sodium diethylenetriamine pentamethylene phosphate are also used in some hair care products, although at very low concentrations. Considering that only trace amounts of phosphorus are used in these products, their contribution to the load to sewer was considered insignificant.

Certain toothpastes contain phosphorus-based ingredients at low concentrations mostly, tetra sodium pyrophosphate, dicalcium phosphate and pentasodium triphosphate and disodium phosphate (Table 1). In most fluorinated toothpastes the active ingredient is sodium fluoride, however, in a limited number of 
108

109

110

111

112

113

114

115

116

117

118

119

120

121

products sodium monofluorophosphate is used and an exact concentration given on the packaging. A survey of the UK market identified 42 common products from 5 companies. Of the 42 products, 12 contained no phosphate, with the others using a range of the aforementioned phosphates. Taking account of the number of products containing each of these substances and the likely percentages of the compounds present in toothpaste (1.6 to $2.5 \mathrm{mg}-\mathrm{P} / \mathrm{kg}$, with a mean of $2.1 \mathrm{mg}-\mathrm{P} / \mathrm{kg}$, based on concentrations provided on the packets) it was possible to estimate the phosphorus content. In the absence of marketing data, it was assumed that the 42 products had equal market share and so a load was calculated using the ratio of the number of products containing phosphate multiplied by the estimated concentration (converted to P) and finally multiplied by an assumed usage per day (5 g toothpaste per person) to derive a per person per day load to sewer (Table 1).

- Table 1 here -

To test the sensitivity of the calculated load a predicted value was generated assuming phosphate concentrations in toothpastes at the highest and lowest reported concentrations.

\section{Phosphorus in foods}

Phosphorus is very widely distributed in both plant and animal foods and is an important mineral for many essential processes in the body. In combination with calcium it is necessary for the formation of bones and teeth. Phosphorus is also involved in the metabolism of fat, carbohydrate and protein, and is essential for efficient absorption of B-group vitamins and in energy metabolism [9]. A review of the available data on the phosphorus content of a range of food and drink was conducted, along with an evaluation of a survey of annual food consumption. Table 2 presents the average consumption, average phosphorus content and estimated intake of phosphorus from that food. As the phosphorus content of a food will vary according to the processing, cooking or quality of the product, an average value was used.

Results from Table 2 indicate an average phosphorus intake from food of around $1.3 \mathrm{~g}-\mathrm{TP} / \mathrm{person} / \mathrm{day}$ of which the majority comes from cereals, dairy and meat products. 
138 In 2003 the National Diet and Nutrition Survey estimated the mean daily intake of phosphorus from food

139 sources for men and women around $1.5 \mathrm{~g}$ and $1.1 \mathrm{~g}$ of phosphorus respectively [15]. Assuming a 50:50

140 population of males and females, an average phosphorus intake from food can be estimated around 1.3

141 mg-TP/person/day. This compares well with the value estimated in Table 2.

142

143 Elemental phosphorus and phosphates also occur in multi-vitamin and mineral supplements at levels 144 between 0.0008 to $0.14 \mathrm{~g}$ [16]. Phosphorus intake from dietary supplements varies in the population; 145 older people tend to have the highest consumption and younger people the lowest. An average 146 phosphorus intake from dietary supplement can be estimated between 0.055 and 0.070 g-P/person/day (a 147 mean of 0.0625 g-P/person/day), [16].

Besides phosphorus derived from unprocessed foods, there is a significant intake of phosphorus via additives in drinks and processed meats amounting to an estimated $0.59 \mathrm{~g}-\mathrm{P} /$ person/day (Table 3). Adding 151 phosphorus derived from natural products, food additives and dietary supplements generates a total of 1521.95 g-P/person/day ingested.

153

154

155

156

157

158 159 160

\section{- Table 3 here -}

The phosphate supplements used within food products (Table 3) are a mixture of soluble and insoluble substances (when ingested) and so it was assumed that for the purposes of source apportionment, they are excreted in urine and faeces on a 50:50 basis.

\section{Phosphorus in detergents}


Phosphates (sodium tripolyphosphate - 25\% P for dry detergents or sodium/potassium phosphates for

162 liquid detergents - 19\% P for trisodium phosphate) have been traditionally used in detergents as builders,

163 binding polyvalent cations such as calcium and magnesium ions, which otherwise interfere with the

164 surfactant's properties.

165

166 The use of phosphate in household detergents has reduced in recent decades [18]. In the 1990s, legislation

167 and voluntary agreements in the EU encouraged the development of alternative non-phosphate laundry

168 detergents. These phosphate free laundry products use zeolite-based detergents together with the

169 associated necessary co-builders. The detergent industry has sought to reduce or replace phosphate in

170 laundry products since alternative products are now available and already dominate the market [19], with

171 levels to be limited to a maximum of $0.4 \%$ as of 2015 [18]. Consequently, phosphorus-based laundry

172 detergents tend now to be restricted to use in some tablet formulations and in supermarket 'own-label'

173 brands. Earlier studies have shown that over the last decade the phosphate based products in laundry

174 detergent have been reducing with estimates of them only representing between $19 \%$ [20] and $45 \%$ [21]

175 of the market in the UK. As the ban on phosphate-based laundry cleaning products approaches, this value

176 is expected to decrease further and the most up to date estimate of 3,360 tonnes-P/year was provided by

177 the detergent industry for the Defra consultation on the phosphate ban [18]. Dividing this figure by the

178 estimated UK population connected to sewer of 59,382,016 provides an estimate of 0.155 g-P/person/day

179 [22].

180

181 The automatic dishwashing detergent market evolved separately from that of laundry detergents. It is 182 currently the view of the detergent industry that phosphate alternatives for automatic dishwashing 183 detergents are inferior and therefore require greater energy during the washing process [19]. The use of 184 phosphorus based products for automatic dishwashers is therefore very high and represents $96 \%$ of the 185 current UK market share in terms of product sold [23]. The percentage of phosphate in phosphorus based 186 domestic detergent products is around 30\%, mainly in the form of sodium tripolyphosphate or tri sodium 187 phosphates [24]. A low and high estimate of automatic dishwashing phosphorus used in the UK of 3,600 
188

189

190

191

192

193

194

195

196

197

198

199

200

201

202

203

204

205

206

207

208

209

210

211

212

213

214

and 4,000 tonnes-P/year has been estimated [18]. Taking an average value of 3,800 tonnes of phosphorus/year and dividing by the UK population connected to sewer generates an estimate of 0.175 gP/person/day.

Phosphonates are also often found in household detergent products. The most common phosphonates used as chelating agents and scale inhibitors are:

- $\quad$ aminotris(methylene phosphonic acid) (ATMP) - 31\% P,

- 1-hydroxyethylidene diphosphonic acid (HEDP) - 28\% P and

- diethylenetriamine penta(methylene phosphonic acid (DTPMP) - 27\% P

An average P content in phosphonate detergents was therefore calculated as $29 \%$ and used for subsequent calculations. It has been reported that $81 \%$ of laundry products and $4 \%$ of dishwasher products contain phosphonates, at a typical concentration of $2.5 \%$ phosphonate by weight [24] significantly less than phosphates where present.

Based on assumptions regarding per person use of detergents (2.1 g/d automatic dishwashing detergent; $20.8 \mathrm{~g} / \mathrm{d}$ laundry detergent), the percentage of products containing phosphonates (4\% for automatic dishwashers and $81 \%$ of laundry detergents), the possible phosphonate content (assumed to be 30\% for all detergents where phosphonates are used) and its composition (29\% P), it is possible to estimate a per person per day loading of phosphonates to sewer of 0.0006 g-P/person/day for automatic dishwashing detergents and $0.12 \mathrm{~g} /$ person/day for laundry detergents (Table 4).

- Table 4 here -

\section{Water supply source of phosphorus}

To meet new WHO drinking water standards for lead in the UK (25 $\mu \mathrm{g}-\mathrm{Pb} / \mathrm{l}$ until December 2013; $10 \mu \mathrm{g}$ $\mathrm{Pb} / \mathrm{l}$ thereafter) phosphate is dosed into the main water supply. The majority of the UK's water supply is now dosed with between 1 and 2 mg-TP/l as orthophosphoric acid or sodium phosphate [26]. Not all of 
the added phosphate reacts with the lead present in the plumbing pipework and after sufficient time, an equilibrium concentration at the tap is achieved (i.e. the concentration dosed will equal the concentration observed at the tap) which can allow dosing concentrations to be reduced, whilst still maintaining compliance with the lead standard. As a consequence residual concentrations will be discharged to sewer, via the water supply. A maximum level of phosphorus at the tap allowed under the Drinking Water Directive is $2.2 \mathrm{mg} / \mathrm{l}[26]$.

A recent survey of 13 water companies serving a population of 40 million reported $91 \%$ of that population to be receiving phosphorus-dosed water. Average target concentrations per company ranged by a factor of around two from ca. $0.7 \mathrm{mg} / \mathrm{l}$ phosphorus to up to $1.9 \mathrm{mg} / \mathrm{l}$, with an average dose across all 22513 companies being $0.91 \mathrm{mg}-\mathrm{P} / \mathrm{l}$ [26]. This range is likely to reflect chemical factors influencing plumbosolvency as well as background levels of phosphate in the raw water. For the source apportionment exercise the average concentration was used and converted to a per person load to sewer by calculating a load based on an assumption of $91 \%$ of the population receiving tapwater containing an average of 0.91-mg-P/l and using 150 l/person/day, then dividing by the UK population connected to sewer [26]. This generates a value of 0.13 g-P/person/day. In terms of total load to STW, however, it

231 should be noted that not just domestic water supply is dosed with phosphorus, all water supplied to a catchment is actually dosed, including that supplied to offices, industry and commercial premises and so the overall contribution to STW is actually higher.

\section{Food waste}

236 A recent Waste Resources Action Programme (WRAP) survey estimated food waste disposed to sewer

237 for the UK and included annual figures for a range of food stuffs including carbonated drinks, milk, cereals, gravy, puddings and fruit drinks [27]. These figures were matched to phosphorus content 


\section{Human excreta}

244 The human body requires typically 0.55 g-P/day [28], the rest is excreted in faeces or urine. The amount

245 of phosphorus excreted by a person depends upon the diet and age of the individual. Studies have

246 indicated that for a western population, the average amount of phosphorus in urine is in the region of 0.9

$247 \mathrm{~g}$-P/person/day and in faeces $0.5 \mathrm{~g}-\mathrm{P} /$ person/day [29, 30]. In the absence of data to accurately apportion

248 food additives between the urine and faeces, it was assumed that the phosphorus-based additives

249 consumed as part of the daily diet were excreted in equal proportions between the urine and faeces.

250 Earlier apportionment exercises assumed all of the additives would be excreted in the urine [22] but there 251 was no actual basis for this assumption.

252

\section{Total domestic contribution of phosphorus load to STW}

254 In order to put domestic contribution to STW into perspective, it is necessary to estimate loads entering 255 an STW. The key parameters for accurate estimates of phosphorus loads to STW are the volume of 256 wastewater entering a STW per person (a sum of domestic, infiltration, runoff, commercial and industrial 257 flows) and the mean concentration of phosphorus in crude sewage. Based on a per person volume to 258 STW of $250 \mathrm{l} /$ person/day and a reported influent phosphorus concentration of $8.25 \mathrm{mg}-\mathrm{P} / \mathrm{l}$ [22] it is 259 possible to calculate a per person contribution to STW of 2.3 g-P/person/day.

\section{Source apportionment}

262 Table 5 presents the data used for calculating loads to sewer. By combining estimates of per person 263 phosphorus load discharged to sewer from domestic households with the population served by mains 264 sewerage, loads of phosphorus to sewer on a tonnes/year basis can be generated. Furthermore, based on 265 information regarding estimates of total per person flow to STW and measured concentrations, a total 266 load to STW can also be calculated. This allows domestic loads to be put into perspective regarding their 267 significance of the overall load being received for treatment at the STW. 


\section{Results}

273 Faeces and urine combined (including the contribution of food additives) contribute 69\% of the overall

274 load to sewer from domestic sources; with contributions from the 'natural' diet of $40 \%$ of the domestic 275 load (Figure 1).

\section{- Figure 1 here -}

After removing half the contribution of food additives to measured urine loads to sewer (unlike earlier studies where all food additive contributions were subtracted from the overall urine load - [22]), urine is 281 still the predominant source of phosphorus contributing an estimated $30 \%$ considered to be derived from a 'natural diet'. Additives to food and drinks, however, are estimated to contribute a significant phosphorus source from domestic inputs to sewer (29\%). The total excretion rate of 1.4 g-P/person/day added to the average daily requirement of $0.55 \mathrm{~g}-\mathrm{P} /$ person/day adds up to a total phosphorus intake of $1.95 \mathrm{mg}-\mathrm{P} /$ person/day which compares well with the overall estimated dietary intake of natural diet (1.32 g-P/person/day), supplements (0.0625 g-P/person/day) and food additives (0.59 g-P/person/day) of 1.97 g-P/person/day). The closeness of the two estimates generated independently provides confidence in the loads calculated and suggests that the apportionment from human sources, particularly the relatively high tap water dosing range from $6 \%$ to $14 \%$, with food scraps and personal care products of minor

291 significance. Excluding phosphonates from the apportionment reduces the contribution of domestic 292 laundry cleaning products to $8 \%$. 
For toothpastes, classified as 'personal care products', loads to sewer from domestic sources were considered to be extremely low (approximately $1.5 \%$ of total domestic load to sewer) compared with other inputs dominated by human sources. A sensitivity test assuming all phosphate-containing products had phosphorus concentrations at the lowest and highest concentration generated a load between 0.009 and $0.05 \mathrm{mg}-\mathrm{P} /$ person/day (equivalent to between $0.4 \%$ and $2.4 \%$ of the overall load).

Loads for each source may be calculated and percentage contribution derived (Table 5). In addition, by estimating total loads entering STW based on multiplying measured influent concentrations (8.25 mg-P/l) by total population connected to the sewer and estimate per person flow to UK STW (150 l/person/day) it is possible to determine the significance of the domestic load. Table 6 shows that approximately 44,000 tonnes of phosphorus are discharged to sewer each year from domestic sources. Compared with estimates of total loads to sewer, domestic sources are estimated to contribute the entirety of the input. However, it should be noted that a proportion of the phosphorus discharged to sewer will be lost via combined sewer overflows (CSOs) which discharge directly to surface water when storm events lead to rainfall volumes entering combined sewerage systems exceeding its capacity. Recent source apportionment modelling for the UK (unpublished data) suggests that as much as 85 tonnes-P/year may be lost to surface water from

311 domestic sources. A further loss from the sewerage system is as a result of misconnections, where wastewater is inadvertently plumbed into surface water drains. A value of $5 \%$ of the load has been previously estimated as the possible load lost via misconnections [18], although it was acknowledged that no reliable data exists. Using these figures reduces the domestic load to STW to approximately 42,000 tonnes-P/year equivalent to $93 \%$ of the total load estimated to enter STW. These estimates suggest that inputs from surface water runoff, industrial and commercial (town centre) sources are not significant.

317 This prediction is considered further in the discussion below. 
323 From a phosphorus management point of view a number of key observations may be made based on the

324 results presented above. Firstly, for regulators it appears that inputs via food additives ingested then

325 excreted is a potentially significant domestic source of phosphorus to STW. Although the HMSO report

326 was published in 1993, more recent data from around the world corroborates the fact that the dietary

327 intake of phosphorus via additives is significant. Uribarri and Calvo [33] report that additives present in

328 restructured meat (e.g. chicken nuggets and hot dogs) processed and spreadable cheeses, 'instant'

329 puddings and sauces could elevate phosphorus sources in the diet to $0.47 \mathrm{~g}-\mathrm{P} / \mathrm{day}$, but depending on the

330 diet could increase intake by as much as $1.0 \mathrm{~g}-\mathrm{P} /$ day. It needs to be noted that diets vary considerably

331 between countries, with America sitting at an extreme end of the spectrum of natural to processed food 332 diet; however, similar findings have been published in Spain [34] and Brazil [35]. There are no recent 333 reports for dietary intake of phosphorus in the UK, but as the UK tends towards a US-style dietary regime 334 dominated by processed foods, phosphorus intake from food additives cannot be expected to decrease in 335 the near future. Control of the use of phosphorus-based additives in foods could therefore offer an 336 important policy option for the reduction of phosphorus loads entering STW. The phosphorus is added to 337 foods primarily for aesthetic and preservation reasons, to maintain 'juiciness', as an emulsion stabiliser, in 338 cure colour development and extend shelf life or in colas where it is used as an acidity regulator. In many 339 cases, a move away from processed foods or use of alternatives would reduce phosphorus from this 340 source.

342 Food disposed to sewer is estimated to total 567 tonnes/year, amounting to only $1.3 \%$ of the total 343 domestic load, although, it is largely avoidable. There are no other UK data to support these estimates; the 344 only available data for phosphorus discharged in food waste to sewer specifically are over 10 years old at 345 the very least and for non-UK locations. These put estimates between 0.1 and 0.4 g/person/day [36-38] compared with $0.03 \mathrm{~g} /$ person/day calculated for this source apportionment exercise. However, it may be considered that this older data may be out of date and not necessarily relevant to the UK situation as, unlike the UK, some countries use food disposal units which encourage the disposal of food waste to 
sewer. Overall, it was considered that the value generated for this project was more reliable and therefore used for source apportionment purposes.

The contribution of phosphorus from household detergents is a dynamic variable owing to the agreed restriction on phosphorus in laundry cleaning products in the UK as of 2015, where phosphorus content (as phosphates) will be limited to a maximum $0.4 \%$ by weight. This combined with a voluntary move towards phosphate-free, zeolite-based alternatives in laundry detergents over the past two decades has seen the contribution of this source to phosphorus loads to sewer decrease significantly. However, the 'phosphate free' detergents do contain a small proportion of phosphonates (typically $2.5 \%$ by weight in the detergent product) which contain phosphorus (typically 29\% P) in a form considered to have less impact on the aquatic environment owing to its likely accumulation in sludge rather than discharge into water via effluents [24]. Consequently, contributions of phosphorus to domestic loads from this source will not decrease to zero. A current estimate of 0.12 g-P/person/day corresponds to an approximate $7 \%$ contribution of domestic phosphorus loads to sewer from domestic laundry detergents, assuming $81 \%$ of laundry detergents contain phosphonates [25]. Assuming a 100\% usage would increase loads to 0.15 gP/person/day and the overall contribution to phosphorus loads to sewer to $8 \%$.

Automatic dishwashing detergents are estimated to contribute $8.7 \%$ of the phosphorus load to sewer from domestic sources but that figure is expected to rise over time as the market is currently dominated by phosphorus-based detergents (96\% of the market) and the ownership of dishwashers is continuing to rise in the UK, from the currently estimated rate of $40 \%$ household ownership at the moment [22]. There is the potential for a doubling of the contribution from this source as the market comes to maturity in the future. Many other countries in Europe and elsewhere have already put restrictions on phosphorus-based automatic dishwasher detergents and so there are already precedents for switching to alternatives, although there are concerns from the phosphate industry that alternative products are inferior in their effectiveness [39]. 
In the UK $91 \%$ of potable water is dosed with typically $1 \mathrm{mg}-\mathrm{P} / \mathrm{l}$ to meet forthcoming drinking water standards for lead which are being reduced to $10 \mu \mathrm{g} / \mathrm{l}$ in December 2013. The phosphorus dosed into the mains supply at water treatment works reacts with lead to form insoluble phosphate minerals and so prevent the dissolution into the water supply. The method is highly effective with $99 \%$ compliance with the standard [26]. Phosphorus dosing is employed owing to the cost of finding and replacing residual lead pipework both external to and within properties. In the UK water companies are responsible for lead pipe between the main and a property boundary, but the house owner is responsible for lead between the property boundary and the tap, where samples for compliance monitoring are taken. Without phosphorus dosing, to be completely effective in meeting the new lead standard, all residual lead pipe, as well as potentially lead soldered joints and brass fittings would need to be replaced [26]. Estimates for one water company serving a population of approximately 7 million, amounted to $£ 890$ million to replace company and householder lead pipes [26]. It is therefore considered that the currently most cost effective solution is to continue to dose with phosphorus. Recent advances in chemical lining technologies may, however, offer a cheaper alternative to lead pipe replacement and could find more widespread use in the future [26]. Assuming an average per person domestic daily use of drinking water of 150 litres, phosphorus contributions from this source to sewer loads is approximately $6 \%$ of the total domestic load. Earlier estimates for all tap water dosed for use by domestic, commercial, light industry and industrial use (amounting to 250 l/person/day) estimated loads contributing up to $10 \%$ to STW influent loads [22]. Given the reported concentration of phosphorus entering STW is approximately $8.25 \mathrm{mg}-\mathrm{P} / \mathrm{l}$ and more up to date mean dosing concentrations are reported as $0.91 \mathrm{mg}-\mathrm{P} / \mathrm{l}$ [26] then the overall contribution to STW loads is likely to be closer to $11 \%$.

Comparing the domestic load with that predicted to be entering STW suggests that they comprise 93\% of the total load to STW. Other potential sources of phosphorus to STW include road runoff, industrial sources (e.g. chemicals, food and drink, laundrettes, metal processing) and commercial and town centre activities such as bars, restaurants, offices, hospitals and car washes. However, road and roof runoff contributes a significant amount of the additional flow to STW which makes up the difference between 
403

404

405

406

407

408

409

410

411

412

413

414

415

416

417

418

419

420

421

422

423

424

425

426

427

428

the measured per person flow (250 l/day) and the domestic flow (150 l/d). Concentrations of phosphorus in runoff, however, are not particularly high. For example $0.66 \mathrm{mg}-\mathrm{P} / \mathrm{l}$ has been reported for developed urban areas [40] around 10 times less than measured concentrations at STW. The load from this source is therefore unlikely to be a major contribution. Industrial discharges may have high phosphorus concentrations, but only contribute (generally) small flows to sewers compared with domestic discharges and runoff. It has been reported elsewhere that industrial contributions only account for $6 \%$ of the load to sewer, but will vary depending on the catchment [22]. The limited data therefore suggest that other contributions of phosphorus from sources other than domestic are relatively minor in magnitude.

Summing all of the domestic contributions comes to a total of ca. 42,000 tonnes-P/year entering STW after accounting for losses from CSOs and misconnections. The total load of phosphorus considered to be derived from preventable sources (tap water dosing, food additives and waste, detergents and personal care products) amounts to over 25,000 tonnes (including phosphonates), approximately 52\% of the total load to STW. These estimates show the potential impact of source control on reducing the phosphorus load to STW should such measures be considered cost effective and can be employed to their maximum extent.

To meet EU legislation most UK STW serving populations over 10,000 apply some form of phosphorus reduction to meet effluent discharge limits of 1 or $2 \mathrm{mg}-\mathrm{P} / \mathrm{l}$. Consequently not all phosphorus entering a STW is discharged in the effluent, a significant proportion is present within the sludge. Estimates (2007) of the loads of phosphorus discharged into receiving waters suggest a range from 25,300 to 34,800 tonnes-P/year [41]. Phosphorus reduction at STW has been escalating under the WFD and so loads discharged from STW are continually reducing and so possibly tending towards the lower end of the estimated range reported. Overall loads of phosphorus to receiving waters and their impacts on compliance with WFD standards is the subject of a follow up paper to this one. 
429

430

431

432

433

434

435

436

437

438

439

440

441

442

By comparison, it has been reported that almost 12,000 tonne-P/year are discharged to surface waters from agriculture [41]. Overall it is evident that source control has the potential to substantially reduce the loads of phosphorus to STW and thence to receiving waters.

\section{Conclusion}

As part of a balanced phosphorus management plan to reduce discharges to the environment which seeks the most cost effective measures to meet WFD water quality requirements and conserve reserves of an essential element, source control options will need to be considered in concert with end-of-pipe STW treatment and reductions in diffuse agricultural discharges. The data presented here suggests significant reductions in phosphorus loads to STW may be achieved by seeking alternatives to, or reductions in the use of phosphorus in automatic dishwashing detergents, dosing of tap water and in food additives. Complete elimination of phosphorus from these sources to sewer could provide up to around a 50\% decrease in loads to sewer from domestic sources. The effectiveness of source control has been demonstrated in the UK (and other countries) via restrictions on the use of phosphorus in laundry detergents and many other countries have extended controls to phosphorus-based automatic dishwashing detergents. It is therefore recommended that in light of long term phosphorus management, both in terms of sustainability of supply and reducing environmental impacts, further source control options should be considered as part of WFD programmes of measures.

\section{List of Tables:}

Table 1 Phosphorus in toothpaste contribution to loads to sewer

Table 2 Source of phosphorus in the average British diet (excluding additives)

Table 3 Phosphorus additive intake via diet. Data from [17] and there in

Table 4 Use of phosphonate based detergents in households in the UK and estimated levels of phosphorus released to sewer 
Table 6 Estimation of domestic phosphorus load to UK STW

457

458

459

460

List of Figures:

Figure 1 Tonnes-P/year discharged to sewer from domestic sources and \% contribution to total load (food additive sources have been separated from urine and faeces loads)

\section{References}

[1] Cordell D. and White S. Peak Phosphorus: Clarifying the key issues of a vigorous debate about long-term phosphorus security. Sustainability 3 (2011), pp. 2027-2049.

[2] UKTAG, UK Technical Advisory Group on the Water Framework Directive, UK Environmental standards and conditions (phase 1), Draft provided to groups and organisations, for review and comment (SR1), 2006.

[3] Environment Agency, Water Framework Directive classification of rivers for 2008. Available at: http://www.environment-agency.gov.uk/research/planning/34383.aspx. Accessed 29/10/12.

[4] Defra, Mapping the problem. Risks of diffuse water pollution from agriculture. Department for Environment, Food and Rural Affair, London. June 2004.

[5] Water UK, Responding to tighter regulation - The future of trade effluent charging. Scoping study produced by Atkins Limited, June, 2008.

[6] Defra, Explanatory Memorandum To The Detergents Regulations 2010, No. 740 Explanatory memorandum has been prepared by the Department for Environment, Food and Rural Affairs and is laid before Parliament by Command of Her Majesty, 2010.

[7] WHO, World Health Organization Guidelines for Drinking Water Quality. 4th Edition. ISBN 978 924 1548151, 2011.

[8] EWG, 2012. Website accessed May 2012.

http://www.ewg.org/reports/skindeep2/report.php?type=INGREDIENT\&id=231

[9] IMFNB, Institute of Medicine. Food and Nutrition Board. Dietary Reference Intakes for Calcium, Phosphorous, Magnesium, Vitamin D, and Fluoride. National Academy Press, Washington, DC. 1997.

[10] NDNS, National Diet Nutrition Survey: headline results from Year 1 (2008/2009) Monday 2 August 2010.

[11] Cupisti A, Morelli E, D'Alessandro C, Lupetti S, and Barsotti G., Phosphate control in chronic uremia: don't forget diet. Journal of Nephrology, 16 (2003), pp. 29-33.

[12] USDA. United State Department of Agriculture. SR234 - Reports by single nutrients, Phosphorus, $2007 . \quad$ Available at: https://www.ars.usda.gov/SP2UserFiles/Place/12354500/Data/SR24/nutrlist/sr24a305.pdf; (Accessed 29/10/12).

[13] EuroFIR. European Food Information Resource, Food composition databases, 2007. Available at: http://www.eurofir.net/food_information/food_composition_databases. (Accessed 29/10/12).

[14] FSA. Food Standards Agency, McCance \& Widdowson's Composition of Foods 
Integrated Dataset (CoF IDS), 6 ${ }^{\text {th }}$ Summary Edition, 2002.

[15] NDNS, The National Diet \& Nutrition Survey: adults aged 19 to 64 years Vitamin and mineral intake and urinary analytes. Volume 3, A survey carried out in Great Britain on behalf of the Food Standards Agency and the Departments of Health by the Social Survey Division of the Office for National Statistics and Medical Research Council Human Nutrition Research, 2003.

[16] FSA, US Food Standards Agency. Phosphorus and the diet, 2007 (http://www.eatwell.gov.uk) (accessed June 2012).

[17] Henderson, L., Irvin, K., Gregory, J. The National Diet \& Nutrition Survey: adults aged 19 to 64 years, Vitamin and mineral intake and urinary analytes, HMSO: London, 2003.

[18] Defra, Consultation on options for controls on phosphates in domestic laundry cleaning products in England. Department for Environment, Food and Rural Affairs, Nobel House, 17 Smith Square, London SW1P 3JR, 2008.

[19] AISE, Annual review 2006 - A network of expertise for sustainable future. International Association for Soaps, Detergents and Maintenance Products (2006).

[20] WaterSense, A public awareness campaign in Scotland, 2005-06, Final report, 2006.

[21] RPA, Non surfactant organic ingredient and zeolite-based detergents. RPA final report prepared for the European Commission, J480b/detergents, 30 June 2006.

[22] Comber, S., Blackwood D., Gilmour D., Issacs J., Piekarniak L., Phosphorus Lifecycle Management (10/SL/02/9). UK Water Industry Research (UKWIR). 1 Queen Anne’s Gate, London, UK. ISBN: 184057570 0, 2010.

[23] UKCPI, UK Cleaning products industry association, builders in laundry detergents products, 2006.

[24] HERA, Phosphonates (CAS 6419-19-8; 2809-21-4; 15827-60-8), Draft, Human \& Environmental Risk Assessment on ingredients of European household cleaning products, September 2004.

[25] Mintel (2007) Clothes washing detergents, market intelligence, January, 2007.

[26] Comber, S., Wakefield, J., Issacs, J. and Blackwood, D., Alternatives to Phosphate for Plumbosolvency Control (12/DW/04/12). UK Water Industry Research, 1 Queen Anne’s Gate, London. ISBN: 184057622 7, 2012.

[27] WRAP, 2009, Down the Drain (WRAP Project EVA063). Report prepared by WRAP, Banbury.

[28] NHS. The National Health Service recipe book, London: HMSO, 2001.

[29] Balmer, P, and Hultman, B., Control of phosphorus discharges: present situation and trends, Hydrobiologia. 170 (1998), pp. 305-319.

[30] Jonsson H., Stintzig A.R., Vinneras B. and Salomon E., Guidelines on the use of urine and faeces in crop production, EcoSanRes, Stockholm Environment Institute, 2003.

[31] Ofwat. Future impacts on sewer systems in England and Wales summary of a hydraulic modelling exercise reviewing the impact of climate change, population and growth in impermeable areas up to around 2040. A report prepared for Ofwat, 2011.

[32] Defra. Future Water: The Government's water strategy for England. Department for Environment Food and Rural Affairs, HMSO, UK, 2008.

[33] Uribarri, J. and Calvo, M.S., Hidden sources of phosphorus in the American diet: Does it matter in nephrology? Seminars in dialysis, 16 (2003), pp.186-188.

[34] Moreno-Torres, R., Ruiz-Lopez, M.D., Artacho, R., Oliva, P., Baena, F., Lopez, C., Dietary intake of calcium, magnesium and phosphorus in an elderly population using duplicate diet sampling vs food composition tables. Journal of Nutritional Health and Aging. 5 (2001), pp. 253-255. 
538

539

540

541

542

543

544

545

546

547

548

549

550

551

552

553

554

555

556

557

558

559

560

561

562

563

564

[35] Ribeiro, M.A., Stamford, T.L. and Filho, J.E., Nutritive value of collective meals: Tables of food composition vs laboratory analysis. Reviews of Saude Publica. 29 (1995) pp.120-126.

[36] Henze M., Waste design for households with respect to wastewater and solid waste. Asian conference on waster and waste management, Tehran, 1998.

[37] Minnesota Pollution Control Agency, Detailed Assessment of Phosphorus Sources to Minnesota Watersheds - Point Sources, February 16, 2004 Project: 23/62-853 POTW 010. http://www.pca.state.mn.us/publications/reports/pstudy-appendix-b.pdf. Accessed, $4^{\text {th }}$ May, 2012.

[38] Metzner, G., Phosphates in municipal wastewater: An analysis of input and output in sewage treatment. Tenside surfactants detergents. 38(6), (2001), pp.360.

[39] CEEP. Centre Europeen d'Etudes des Polyphosphates, Phosphates in Automatic Dishwasher Detergents. August 2007 report.

[40] Mitchell, G., MacDonald, A. and Lockyer, J., The Quality of Urban Stormwater in Britain and Europe: Database and Recommended Values For Strategic Planning Models. University of Leeds, 2009. http://www.geog.leeds.ac.uk/projects/nps/reports.htm. Accessed, May $10^{\text {th }} 2012$.

[41] White P.J. and Hammond H.P. Updating the estimate of the sources of phosphorus in UK waters. Defra project WT0701CSF. Department for Environment Food and Rural Affairs, 2007.

\section{Acknowledgements:}

This project was initiated by UKWIR but delivered in collaboration with SNIFFER, UKTAG, the Environment Agency and SEPA. The authors wish to thank these contributors for their support with this project, and in particular Mr Paul Henderson of Dwr Cymru/Welsh Water who client managed the project. 


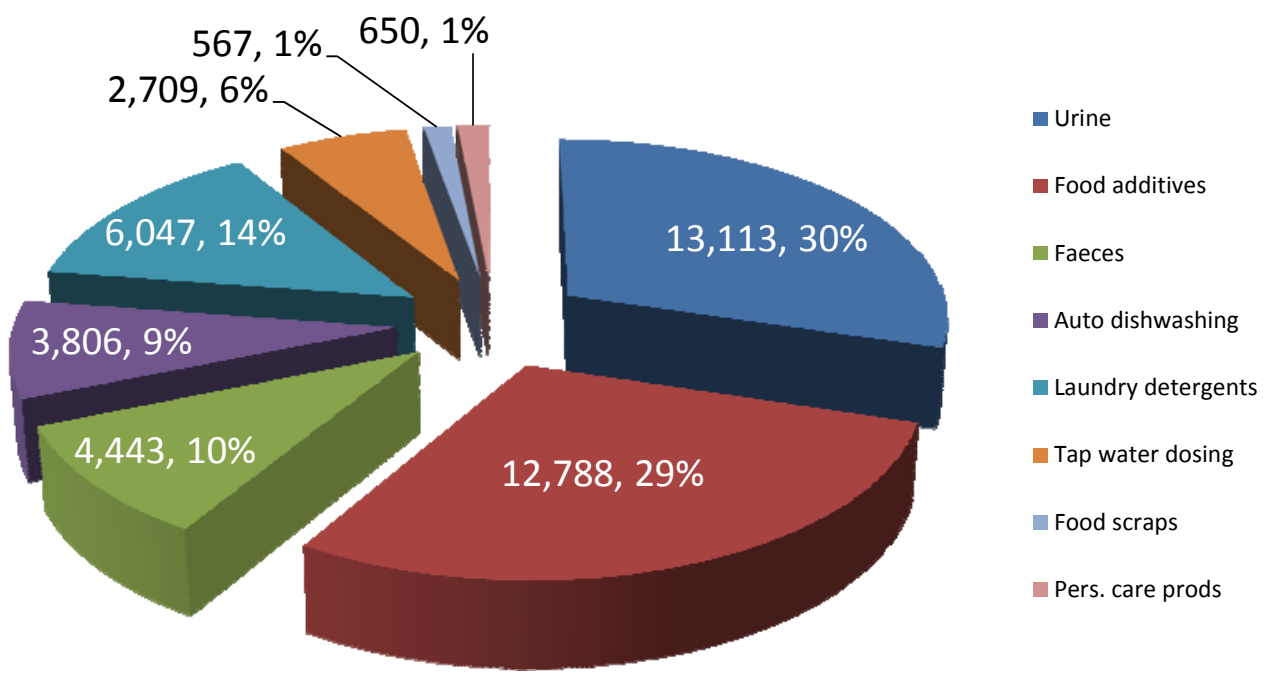

565

566

567

568

569
Figure 1 Tonnes-P/year discharged to sewer from domestic sources contribution to total load (food additive been separated from urine and faeces loads) and $\%$ sources have

Table 1 Phosphorus in toothpaste contribution to loads to sewer

\begin{tabular}{|l|c|c|c|c|}
\hline Substance & $\begin{array}{l}\text { No. of } \\
\text { products } \\
\text { containing } \\
\text { phosphates }\end{array}$ & $\begin{array}{c}\text { Approximate } \\
\text { \% in product }\end{array}$ & $\begin{array}{l}\text { Average P } \\
\text { content } \\
\text { (mg-P/g) }\end{array}$ & g-P/person/day \\
\hline Phosphate-free & 12 & & 1.98 & 0.0022 \\
\hline Sodium Monofluorophosphate & 9 & & 4.5 & 0.0021 \\
\hline Dicalcium Phosphate Dihydrate & 4 & 2.5 & 14 & 0.012 \\
\hline Tetrasodium Pyrophosphate & 7 & 3 & 5.6 & 0.0013 \\
\hline Disodium Pyrophosphate & 2 & 2 & 8.5 & 0.0030 \\
\hline Trisodium Phosphate & 3 & 1.5 & 2.5 & 0.0015 \\
\hline Penta Sodium Triphosphate & 5 & 1 & & 0.022 \\
\hline Total & 42 & & & \\
\hline
\end{tabular}

${ }^{a}$ taking account of phosphorus content in each of the chemical multiplied by the percentage of the chemical in the product.

${ }^{\mathrm{b}}$ assumes $5 \mathrm{~g}$ of toothpaste used per person per day, and all of phosphate containing product is released to sewer. 

(excluding additives)

\begin{tabular}{|c|c|c|c|c|}
\hline & $\begin{array}{c}\text { Average } \\
\text { consumption } \\
\text { (g/d) [9] }\end{array}$ & $\begin{array}{c}\text { P content } \\
(\mathrm{mg} / 100 \mathrm{~g}) \\
{[10,11,12]}\end{array}$ & $\begin{array}{l}P \text { intake } \\
(g / d)\end{array}$ & $\begin{array}{l}\% \text { of daily } \\
\text { intake }\end{array}$ \\
\hline Cereals & 252 & 130 & 0.328 & 25 \\
\hline $\begin{array}{l}\text { of which } \\
\text { - Bread }\end{array}$ & 110 & 120 & 0.132 & 10 \\
\hline Meat \& meat products & 161 & 200 & 0.322 & 24 \\
\hline Milk \& cream & 290 & 95 & 0.276 & 21 \\
\hline $\begin{array}{l}\text { of which } \\
\text { - whole milk } \\
\text { - semi-skimmed milk } \\
\text { - skimmed milk } \\
\text { - yogurt }\end{array}$ & $\begin{array}{c}68 \\
134 \\
30 \\
28 \\
\end{array}$ & $\begin{array}{l}93 \\
94 \\
94 \\
98 \\
\end{array}$ & $\begin{array}{l}0.063 \\
0.126 \\
0.028 \\
0.028 \\
\end{array}$ & $\begin{array}{l}5 \\
9 \\
2 \\
2 \\
\end{array}$ \\
\hline Cheese & 20 & 500 & 0.100 & 8 \\
\hline Potatoes (fresh \& processed) & 131 & 60 & 0.079 & 6 \\
\hline Fish & 26 & 215 & 0.056 & 4 \\
\hline Alcoholic drinks & 191 & 25 & 0.048 & 4 \\
\hline $\begin{array}{l}\text { of which } \\
\text { - beers \& lagers }\end{array}$ & 97 & 25 & 0.024 & 2 \\
\hline Soft drinks & 295 & 15 & 0.044 & 3 \\
\hline Fruit & 185 & 20 & 0.037 & 3 \\
\hline $\begin{array}{l}\text { of which } \\
\text { - Fresh apples } \\
\text { - Pure fruit juices }\end{array}$ & $\begin{array}{l}26 \\
50\end{array}$ & $\begin{array}{l}10 \\
17\end{array}$ & $\begin{array}{l}0.003 \\
0.009\end{array}$ & $\begin{array}{l}0 \\
1\end{array}$ \\
\hline $\begin{array}{l}\text { Vegetables excluding } \\
\text { potatoes }\end{array}$ & 26 & 30 & 0.008 & 1 \\
\hline Confectionery & 20 & 90 & 0.018 & 1 \\
\hline Eggs & 0.23 & 210 & 0 & 0 \\
\hline Fats & 26 & 0 & 0 & 0 \\
\hline $\begin{array}{l}\text { of which } \\
\text { - Butter }\end{array}$ & 5 & 0 & 0 & 0 \\
\hline Beverages & 26 & 10 & 0.003 & 0 \\
\hline Sugar \& preserves & 18 & 0 & 0 & 0 \\
\hline Ice cream, desserts \& cakes & 4 & 100 & 0.004 & 0 \\
\hline \multicolumn{3}{|l|}{ Total $P$ intake from food } & 1.32 & g-P/capita/d \\
\hline \multicolumn{3}{|c|}{ Total P intake from food \& dietary supplements [13] } & $1.38-1.39$ & g-P/capita/d \\
\hline
\end{tabular}

Table 3 Phosphorus additive intake via diet Data from [17] and there in

\begin{tabular}{|l|l|c|}
\hline Additive Name & Number & $\begin{array}{c}\text { Dietary intake } \\
\text { (g-P/person/d) }\end{array}$ \\
\hline Sodium and potassium diphosphates & E450a & 0.26 \\
\hline Calcium orthophosphates & E341 & 0.15 \\
\hline
\end{tabular}


585

\begin{tabular}{|l|l|c|}
\hline Sodium and potassium triphosphates & E450b & 0.06 \\
\hline Sodium orthophosphates & E339 & 0.03 \\
\hline Ammonium phosphatides & E442 & 0.03 \\
\hline Sodium and potassium polyphosphates & E450c & 0.03 \\
\hline Orthophosphoric acid & E338 & 0.022 \\
\hline Potassium orthophosphates & E340 & 0.008 \\
\hline Sodium aluminium phosphate basic & E541 & 0.001 \\
\hline Riboflavin 5'-phosphate & E101 & 0.00005 \\
\hline Edible bone phosphate & E542 & 0.0002 \\
\hline Inosine 5- (disodium phosphate) & E631 & 0.0001 \\
\hline Guanosine 5- (disodium phosphate) & E627 & Trace \\
\hline Total & & 0.59 \\
\hline
\end{tabular}

Table 4 Use of phosphonate based detergents in households in the UK and estimated levels of phosphorus released to sewer.

\begin{tabular}{|l|c|c|}
\hline & Dishwashers & Laundry \\
\hline Weight of detergent used & $20 \mathrm{~g}^{\star}$ & $88 \mathrm{~g}^{\star \star}$ \\
\hline Number of washes per day per household [25] & 0.7 & 0.6 \\
\hline $\begin{array}{l}\text { \% of population using dishwashers/washing machines } \\
{[24]}\end{array}$ & 36 & 100 \\
\hline Average household occupancy & 2.36 & 2.36 \\
\hline Total detergent released to sewer per person per day & $2.1 \mathrm{~g}$ & $21.5 \mathrm{~g}$ \\
\hline Percentage of phosphonates [24] & 4 & 81 \\
\hline Percentage of phosphonates in products [24] & 2.5 & 2.5 \\
\hline $\begin{array}{l}\text { Amount of phosphorus discharged per person per } \\
\text { day derived from use of phosphonates (g- } \\
\text { P/capita/day) }\end{array}$ & & \\
\hline
\end{tabular}

* Standard mass of tablet. ${ }^{* \star M a n u f a c t u r e r}$ data for moderately hard waters. *** UK 2011 Census data.

Table 5 Data used for calculating phosphorus loads to sewer

\begin{tabular}{|l|c|l|}
\hline General & Data & Units \\
\hline UK population* & $61,791,900$ & \\
\hline UK connected population [31] & $59,382,016$ & \\
\hline Assumed average flow to WwTW per capita per day [22] & 250 & l/capita/day \\
\hline Domestic water use [32] & 150 & I/capita/day \\
\hline Occupancy* & 2.36 & \\
\hline Measured influent P concentration [22] & $8.25+/-0.9^{* *}$ & mg-P/l \\
\hline
\end{tabular}

* UK 2011 Census data. ${ }^{*} 95^{\text {th }}$ percentile confidence limits on average measured total phosphorus at 
Table 6 Estimation of domestic phosphorus load to UK STW

603

\begin{tabular}{|c|c|c|c|}
\hline Phosphate discharges & P type & $\begin{array}{c}\text { Per capita } \\
\text { discharge to } \\
\text { sewer } \\
\text { (g-P/capita/day) }\end{array}$ & $\begin{array}{c}\text { Annual load } \\
\text { to sewer } \\
\text { (tonnes-Plyr) }\end{array}$ \\
\hline Food additives & & 0.59 & 12,788 \\
\hline Faeces & & 0.21 & 4,443 \\
\hline Urine & & 0.61 & 13,113 \\
\hline \multirow[t]{2}{*}{ Washing machines } & Phosphates & 0.155 & 3,360 \\
\hline & Phosphonates & 0.12 & 2,688 \\
\hline \multirow[t]{2}{*}{ Auto dishwasher } & Phosphates & 0.175 & 3,793 \\
\hline & Phosphonates & 0.0006 & 13 \\
\hline $\mathrm{P}$ dosing of tap water & & 0.125 & 2,709 \\
\hline Food scraps & & 0.10 & 567 \\
\hline Personal care products & & 0.022 & 477 \\
\hline Total domestic load to sewer & & 2.03 & 43,951 \\
\hline Potential loss from mis-connections & & 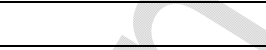 & 2,449 \\
\hline Possible loss via CSOs & & 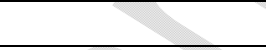 & 85 \\
\hline Estimate of domestic load to STW & & 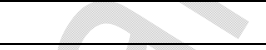 & 41,678 \\
\hline Total measured load to STW & & mean & 44,714 \\
\hline Domestic sources as $\%$ of total load & & 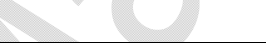 & $93 \%$ \\
\hline
\end{tabular}

604

605

606 